\title{
Journal of the History of Sufism / Journal d'histoire du soufisme, IV, Sufi Dance / La danse soufie. Paris, Librairie d'Amérique et d'Orient, (2004), 312 p.
}

Ève Feuillebois-Piérunek

\section{(2) OpenEdition}

1 Journals

\section{Édition électronique}

URL : http://journals.openedition.org/abstractairanica/6240

DOI : 10.4000/abstractairanica.6240

ISSN : 1961-960X

Éditeur :

CNRS (UMR 7528 Mondes iraniens et indiens), Éditions de l'IFRI

\section{Édition imprimée}

Date de publication : 15 mai 2006

ISSN : 0240-8910

\section{Référence électronique}

Ėve Feuillebois-Piérunek, « Journal of the History of Sufism / Journal d'histoire du soufisme, IV, Sufi Dance / La danse soufie. Paris, Librairie d'Amérique et d'Orient, (2004), 312 p. », Abstracta Iranica [En ligne], Volume 27 | 2006, document 271, mis en ligne le 02 janvier 2007, consulté le 25 septembre 2020. URL : http://journals.openedition.org/abstractairanica/6240 ; DOI : https://doi.org/10.4000/ abstractairanica.6240

Ce document a été généré automatiquement le 25 septembre 2020.

Tous droits réservés 


\title{
Journal of the History of Sufism / Journal d'histoire du soufisme, IV, Sufi Dance / La danse soufie. Paris, Librairie d'Amérique et d'Orient, (2004), $312 \mathrm{p}$.
}

\author{
Ève Feuillebois-Piérunek
}

1 La plus grande partie de ce numéro est consacrée au thème du sama $\bar{a}^{c}$, richement documenté grâce à la diversité des approches employées, des lieux et des époques évoqués dans les nombreux articles de spécialistes mondialement reconnus. Une introduction aurait été la bienvenue, afin de poser la problématique, de synthétiser les différentes contributions et de situer ce recueil par rapport à la documentation existante.

2 Dans «La danse soufie (samã) à l'époque de Mawlânâ », Tahsin Yazici propose une introduction générale au sama $\bar{a}^{c}$ d'après les Manāqib al-'ārifin d'Aflākī.

3 Serge de Beaurecueil, dans « Lendemains d'une expérience malheureuse : le sama $\bar{a}^{\star}$ chez “Abdullâh Ansârî ”, montre comment Anșārī, impressionné par les effets d'un samāc auquel il participa en 1034, fit le choix d'un soufisme de sobriété plutôt que d'ivresse.

4 S'appuyant sur différents ouvrages de Sulamī dont deux encore inédits, Kenneth Honerkamp («Abû 'Abd al-Rahmân al-Sulamî (d. 412/1021): on Samā', Ecstasy and Dance ») étudie le statut juridique, la nature, les principes, caractéristiques et usages du sama $\bar{a}^{`}$ à la charnière du $10^{\mathrm{e}}$ et du $11^{\mathrm{e}} \mathrm{s}$.

5 Pierre Lory («La danse dans l'onirocritique ») se penche sur les traités d'interprétation des rêves, où la danse est comprise de manières diverses selon le contexte. Dans le contexte soufi, elle est considérée comme une expérience de l'extase, et la réserve, plutôt que l'abandon à cette pratique, est généralement de rigueur. 
D'après Dilaver Gürer, « Deux traités par des şeyhulislams ottomans sur la danse », le samā fait l'objet d'un débat passionné au $16^{\mathrm{e}}$ et $17^{\mathrm{e}} \mathrm{s}$. dans l'empire ottoman entre détracteurs et partisans, y compris parmi les autorités spirituelles traditionnelles. Deux contributions différentes à ce débat sont ici analysées, celles de Zembillī Alī Efendī et Kemal Paşa-Zāde.

7 L'article de Mahmud E. Kiliç, "Yaşar Baba, maître de zikr dans le soufisme turc », décrit différentes pratiques de $s a m \bar{a}^{c}$ dans diverses confréries soufies d'Istanbul au début du $20^{\mathrm{e}} \mathrm{s}$., et insiste sur le rôle de Yaşar Baba comme transmetteur de cette pratique.

8 S'appuyant sur une enquête de terrain, Melih Duygulu, «Poésie et danse chez les Bektashis des Balkans ", étudie les traditions musicales, danses et chants des Bektashis de Thrace.

Alberto F. Ambrosio, «La danse des 'derviches tourneurs' et la création d'un espace sacré ", part du concept d'espace sacré, et s'appuie sur le Minhāj al-Fuqarā d'Anqarawī (m. 1631) pour analyser la double relation entre espace et $s a m \bar{a}^{c}:$ le soufi entrant en danse sous l'effet de l'amour divin occupe un espace préalablement sacré, mais il participe aussi activement à la sacralisation de l'univers.

Mostafa Zekri, dans "La 'imâra des Darqâwâ du Maroc: une danse rituélisée (sic)", relate la création, à la charnière du $18^{\mathrm{e}}$ et du $19^{\mathrm{e}} \mathrm{s}$., par le fondateur de la Darqawiyya, d'une danse rituelle, la 'imāra, et en décrit la pratique.

11 Dans une approche alliant cinématographie et sciences sociales, Jean-Claude Penrad, «Chorégraphies mystiques. Vidéographie et relation de rituels: Zanzibar, Comores, Syrie ", décrit et compare sommairement les rituels soufis de Zanzibar, des Comores et de la Syrie, et mène une réflexion anthropologique sur la transe et le langage du corps. "Quand un Bakhsi Kazakh évoque Allah » d'Anne-Marie Vuillemenot étudie l'influence du soufisme sur le chamanisme d'Asie centrale à travers la pratique d'un Bakhsi du Kazakhstan.

13 Pour Françoise Arnaud-Demir, «Entre chamanisme et soufisme : le semâ' des AléviBektachis ", cette pratique serait une synthèse du oyun (danse ou jeu) préislamique et du symbolisme de l'ancienne société turque chamaniste. C'est une évocation de la migration des grues, censée apporter le renouveau du printemps et assurer la survie de la communauté.

Dans sa «Note sur la danse dans les cultes musulmans du domaine sindhî», Michel Boivin montre comment une danse shivaïte comprise comme un moyen d'atteindre la Divinité fut adaptée par les missionnaires soufis et ismaéliens au $13^{\mathrm{e}} \mathrm{s}$. et servit de médiatrice pour diffuser l'islam au sein de la population du Sind. Elle est encore pratiquée aujourd'hui pour expérimenter l'extase ou accomplir des exorcismes.

15 Alexandre Papas, "'Dansez et chantez' : le droit au samā' selon Âfâq Khwâja, maître naqshbandî du Turkestan (XVIIe siècle) », s'intéresse à Āfāq Hुwāja, qui, s'opposant à l'attitude habituellement très réservée des Naqshbandis par rapport au sam $\bar{a}^{c}$, défendit fermement l'usage spirituel du chant et de la danse en s'appuyant sur la Sunna et sur des textes soufis classiques. L'hagiographie de ce maître, Hidāyat-nāma présente le sama $\bar{a}^{c}$ comme une synthèse de technique initiatique, de cérémonie politique et de rite communautaire.

Dans « Les danses naqshbandîs en Asie centrale et au Xinjiang : histoire et actualité » de Thierry Zarcone, on trouvera l'analyse de différents types de $\underline{d i k r}$ et de $s a m \bar{a}^{\dagger}$ observés 
entre 1995 et 2002 dans la vallée de la Ferghana (Ouzbékistan) et au Xinjiang (Chine de l'Ouest) notamment dans les confréries Naqshbandiyya et Jahriyya.

17 Enfin, dans "Samā and Sufi Dance: a Selected Bibliography», A. F. Ambrosio et Th. Zarcone listent les sources secondaires entièrement consacrées au sujet.

INDEX

Thèmes : 8 . Soufisme

nompropre Aflāki, Ansāri

\section{AUTEURS}

ÈVE FEUILLEBOIS-PIÉRUNEK

Sorbonne Nouvelle - Paris III 